\title{
The Splitting 660 km Discontinuity Associated with Lithospheric Delamination in the Northern Part of the North-South Seismic Zone, China
}

Chuansong S. He ( $\sim$ hechuansong@aliyun.com )

China Earthquake Administration

\section{Research Article}

Keywords: discontinuity, lithospheric delamination, NSSZ, CCP

Posted Date: November 16th, 2021

DOI: https://doi.org/10.21203/rs.3.rs-1049354/v1

License: (c) (1) This work is licensed under a Creative Commons Attribution 4.0 International License.

Read Full License 


\section{Abstract}

The north-south seismic zone (NSSZ) is a destructive zone of large-scale earthquakes in China, and the earthquake mechanism associated with deep structures remains unclear. Previous studies have indicated that lithospheric delamination or absence of lithospheres in the western part of the NSSZ may facilitate the eastern extrusion of the Tibetan Plateau and lead to stress accumulation and release. However, the deep process of lithospheric delamination needs to be further clarified. In this study, I collect abundant high-quality teleseismic data recorded by permanent seismic stations and perform common conversion point (CCP) stacking of receiver functions in the north part of the NSSZ. The results show that lithospheric delamination might result in the splitting $660 \mathrm{~km}$ discontinuity and a thickening region of the mantle transition zone (MTZ).

\section{Introduction}

The north-south seismic zone (NSSZ) on the Chinese continent is an important earthquake-prone region. From historically documented records, approximately $1 / 3$ of the larger earthquakes in China have occurred in this area; moreover, the zone is a boundary between the highlands in the western part and lowlands in the eastern part ${ }^{1}$ and is also a strong lateral gradient zone in the gravity anomaly and crustal thickness maps ${ }^{2,3}$.

This study region located in the northern part of the NSSZ includes the Alashan terrane, Qilian orogenic belt, Ordos terrane, Songpan-Ganzi terrane and Western Qinling orogenic belt (Fig. 1), which have undergone a complex tectonic evolution process ${ }^{4}$. The Ordos terrane is a large intracratonic compressional basin ${ }^{5}$ that has been affected by both Pacific plate westward subduction since the Mesozoic and the collision between the South and North China Blocks in the Triassic ${ }^{6}$. In the western part of this region, the Alxa terrane, Qilian terrane and Qaidam terrane assembled and collided during the Late Ordovician to Devonian? 7 Specifically, the eastward extrusion of the Tibetan Plateau due to the collision between the Indian and Eurasian Plates in the Cenozoic might lead to the formation of an earthquakeprone zone in this area ${ }^{8}$.

In this area, a number of geophysical studies have been carried out, such as tomography ${ }^{9}$, shear-wave splitting $^{10}$, receiver functions ${ }^{2}$ and deep seismic sounding ${ }^{11,12}$. A receiver function study revealed that delamination might result in variations in the crustal structure and topography of the mantle transition $z^{2} e^{2}$. A tomographic study revealed high-velocity anomalies in the mantle transition zone, which might be linked with the delamination of lithospheric delamination ${ }^{13}$. To understand the delamination model in this area, I collected abundant high-quality teleseismic data recorded by permanent seismic stations (Fig. 1, insert figure of left panel) and carried out CCP stacking of receiver functions. The results indicate a splitting $660 \mathrm{~km}$ discontinuity and thickening of the MTZ beneath the northern part of the NSSZ, which might have been generated by the deep process of lithospheric delamination. 


\section{Results}

Based on previous tomography 10(He and Santosh, 2017), large high-velocity anomalies and large lowvelocity anomalies (Hv1 and Lv1) are present at depths of 70-200 km (Fig. S1). Hv1 might be the lithospheric root of the Ordos Basin; Lv1 may be absent from the lithosphere in the eastern part of the study region. At depths of 300-700 km, many high-velocity anomalies that may be associated with lithospheric delamination during different periods ${ }^{10}$ are designated Hv2. Three profiles of P-wave velocity perturbation and CCP stacking of receiver functions were created simultaneously along the same location (location of profiles, see left panel of Fig. 1).

The results show that a high-velocity anomaly appears at the MTZ (Fig. 2, upper panel of profiles a, b and c). CCP stacking profiles of receiver functions indicate that the topographic variation of the $410 \mathrm{~km}$ discontinuity is not obvious (Fig. 2, low panel of profiles $a, b$ and c), which is basically consistent with the global average depth ${ }^{15,16}$. In contrast, the topography of the $660 \mathrm{~km}$ discontinuity shows amazing variation at profiles a and b (Fig. 2, lower panel of profiles a and b, blue rectangle); the $660 \mathrm{~km}$ discontinuity splits into multiple interfaces that is distributed at depths from 630 to $800 \mathrm{~km}$, and its amplitude obviously becomes weak (Fig. 2, lower panel of profiles a and b, blue rectangle).

I overlaps two kind profiles (Fig. 3). The results indicate that the high-velocity anomaly (Hv2) almost overlaps the $660 \mathrm{~km}$ discontinuity in profiles a and b, whereas the high-velocity anomaly (Hv2) is basically above the $660 \mathrm{~km}$ discontinuity in profile c, whose variations are relatively small.

The topographies of the $410 \mathrm{~km}$ and $660 \mathrm{~km}$ discontinuities were extracted. The results show a local shallowing region of the $410 \mathrm{~km}$ discontinuity (Fig. 4, a, b, blue rectangular region) and a local deepening region of the $660 \mathrm{~km}$ discontinuity in the middle part of the study region (Fig. 4, c, d, blue rectangular region). The thickness of the MTZ is a thickening region in the middle part of the study region (Fig. 4, e, f, blue rectangle region).

\section{Discussion}

Splitting $666 \mathrm{~km}$ discontinuity. The MTZ is characterized by abrupt changes in seismic velocities, which divide the Earth's upper and lower mantle. Based on seismic investigations, major global seismic velocity discontinuities appear at depths of approximately 410 and $660 \mathrm{~km}$, which boundary the top and bottom of the MTZ ${ }^{18}$. Generally, these discontinuities are considered polymorphic olivine phase change systems. $410 \mathrm{~km}$ discontinuity is linked with a phase transition from olivine to wadsleyite with a positive temperature-pressure gradient (or Clapeyron slope) ${ }^{19}$; when the temperature decreases, the topography of the $410 \mathrm{~km}$ discontinuity will become shallow. In contrast, $660 \mathrm{~km}$ discontinuity is associated with a phase transition from ringwoodite into perovskite and magnesiowüstite with a negative Clapeyron slope $^{20,21}$; when the temperature decreases, the topography of the $660 \mathrm{~km}$ discontinuity will deepen. The non-olivine or garnet-dominant system occurs in a relatively high-temperature environment that may be connected with a positive Clapeyron slope 22,23 ; when the temperature increases, the topography of the 
$660 \mathrm{~km}$ discontinuity will become deepen. A previous seismic study reported two discontinuities around the $660 \mathrm{~km}$ discontinuity or splitting $660 \mathrm{~km}$ discontinuity, suggesting that both phase transitions are occurring ${ }^{24}$.

The splitting $660 \mathrm{~km}$ discontinuity may be associated with both phases occurring in this area. However, the splitting $660 \mathrm{~km}$ discontinuity identified in this study obviously is not two discontinuities (Fig. 2, profiles a and b), and it may be three or four interfaces. Moreover, the amplitude of the $660 \mathrm{~km}$ discontinuity obviously becomes weak, which was first discovered in global seismic observations.

Lithospheric delamination. The lower continental crust, which might be a weak decoupling interface ${ }^{25}$, is suggested to provide a bridge between the felsic upper crust and the mafic/ultramafic upper mantle 26,27 . Under compression, the high-density lithosphere/lower crust might experience viscous dripping or convective removal due to Rayleigh-Taylor/gravitational instability (discrete high-velocity body delamination) or delamination along the weak decoupling interface (plate-like delamination) ${ }^{28,29}$ and contribute to velocity inhomogeneity in the mantle and variations in crustal composition.

A previous receiver function study indicated that the northern part of the NSSZ is not only a crustal thickness gradient zone (Fig. S4, a, white arrow: crustal thinning direction) but also a predominantly felsic lower crust (Fig. S4, b, rectangle region) induced by mafic/ultramafic lower crustal/lithospheric delamination ${ }^{2}$. Tomographic images also indicate lithospheric absence in the western part of the study region induced by lithospheric delamination (Fig. S1, 70-200 km depth sections, Lv1), and several highvelocity anomalies (Hv2) at depths of $300-700 \mathrm{~km}$, which might be associated with lithospheric delamination in this area 10(He and Santosh, 2017). Generally, it is widely accepted that the high-velocity structure or delaminated lithosphere in the MTZ is a cold domain ${ }^{30}$, which might result in a shallowing topography of the $410 \mathrm{~km}$ discontinuity and a deepening topography of the $660 \mathrm{~km}$ discontinuity as well as the thickening of the MTZ in the center part of the this study (Fig. 4). Based on these images, it is suggested that the lithosphere has been delaminated into the MTZ in this area.

\section{Conclusions}

1. The high-velocity anomalies in the mantle transition may lead to the $660 \mathrm{~km}$ discontinuity splitting into multiple discontinuities, which is worth further study.

2. Delaminated lithosphere in the MTZ resulted in thickening of the MTZ.

3. The results identified in this study support the notion that the lithosphere delaminated into the MTZ.

\section{Data And Method For The Ccp Stacking Of Receiver Functions}

A total of 982 teleseismic events were collected in this area, which were recorded by 214 permanent seismic stations of the China Seismic Network from 2007 to 2014 (Fig. 1, insert figure of left panel). The events were limited to $\mathrm{Ms}>5.8$, and the earthquake epicentral distances ranged from $30^{\circ}$ to $90^{\circ}$ for individual event-station pairs. The raw waveforms with a $50 \mathrm{~Hz}$ or $100 \mathrm{~Hz}$ sampling rate were cut from 15 
$\mathrm{s}$ before to $200 \mathrm{~s}$ after the P-wave arrival time and filtered using a Butterworth bandpass filter ranging from 0.1 to $0.2 \mathrm{~Hz}$; waveform sample rates were decimated to $0.1 \mathrm{~s}$. The waveform cross-correlation technique ${ }^{31}$ was employed to select consistent waveform data (an example can be found in Fig. S5). A modified frequency domain deconvolution using a Gaussian factor equal to 1 and a water level equal to 0.01 was employed to extract the receiver functions ${ }^{32}$. Finally, 13335 high-quality receiver functions (for example, please see Fig. S6), whose Ps phase and PPms phase can be clearly seen, were extracted and used for CCP stacking. This dataset is far larger than any dataset used for previous receiver function studies in this area.

A CCP stacking of receiver functions ${ }^{33-35}$ is used to image the MTZ of the northern part of the NSSZ. The piercing points at depths of 410 and $660 \mathrm{~km}$ are calculated by using the IASP 91 1-D velocity model ${ }^{15}$. Spherical coordinates are used to calculate the Ps-P differential time $T_{P s}$ (Ps: PS converted wave, P: Pwave, $T_{P_{s}}$ : travel-time from Ps phase to $P$ phase) ${ }^{34}$. The effect of velocity heterogeneities in the upper mantle is removed by a global 3-D velocity model ${ }^{14}$ and a local 3-D velocity model ${ }^{10}$. Lateral grid intervals of $0.5^{\circ}$ and depth intervals of $1 \mathrm{~km}$ are designed for the CCP stacking of receiver functions, and the migrated receiver functions are searched within a radius of $75 \mathrm{~km}^{36}$.

\section{Data Available}

The CCP stacking data of receiver functions and raw data used in this study can be accessed via https://doi.org/10.5281/zenodo.5638403.

\section{Declarations}

\section{Acknowledgements}

Thanks to the National Key R\&D Plan of China (2017YFC601406) and the Data Management Center of the China National Seismic Network at the Institute of Geophysics and the China Earthquake Networks Center.

\section{Author contributions}

H.C. conducted the conceptualization, data curation, formal analysis, funding acquisition, writing-original draft, writing-review \& editing.

\section{Competing Interests}

The author declares no competing interests.

\section{References}


1. Zhang, P. Z., Deng, Q., Zhang, G., Ma, J. \& Gan, W. Active tectonic blocks and strong earthquakes in continental China. Sci. China D 33, 13-24 (2003).

2. He C. S., Santosh, M., Chen, X. H. \& Li, X. Y. Continental dynamics in a multi-convergent regime: a receiver function study from the North-South-Trending Tectonic Zone of China. Int. Geol. Rev. 56, 525-536 (2014).

3. Zhang, P. Z. A review on active tectonics and deep crustal processes of the Western Sichuan region, eastern margin of the Tibetan Plateau. Tectonophysics 584, 7-22 (2013).

4. Zhao, G. C. et al. Single zircon grains record two Paleoproterozoic collisional events in the North China Craton. Precam. Res. 177, 266-276 (2010).

5. Wang Y. H. et al. Mesozoic lithospheric deformation in the North China block: Numerical simulation of evolution from orogenic belt to extensional basin system. Tectonophysics 405, 47-63 (2005).

6. Ratschbacher, L. et al. Exhumation of the ultrahigh-pressure continental crust in east-central China: Cretaceous and Cenozoic unroofing and the Tan-Lu fault. J. Geophys. Res. 105, 13303-13338 (2000).

7. Xu, Z. Q., et al. Timing and mechanism of formation and exhumation of the Northern Qaidam ultrahigh-pressure metamorphic belt. J. Asian Earth Sci. 28, 160-173 (2006).

8. Deng, Q. et al. Basic characteristics of active tectonics of China. Sci. China D 46, 356-372 (2003).

9. Liu, J. H., Liu, F. T., Wu, H., Li, Q. \& Hu, G. Three dimensional velocity images of the crust and upper mantle beneath north-south zone in China. Chinees J. Geophys. 95, 916-925 (1989).

10. He, C. S. \& Santosh, M., Intraplate earthquakes and their link with mantle dynamics: Insights from Pwave teleseismic tomography along the northern part of the North-South Tectonic Zone in China. $C$. R. Geosci. 349, 96-105 (2017).

11. Li, S. L. et al. A Preliminary Study on Crustal Velocity Structures of Maqin-Lanzhou-Jingbian Deep Seismic Sounding Profile. Chinese J. Geophys. 45, 209-216 (2002).

12. Gao, R. et al. Tectonic Relationships between the Zoigê Basin of the Song-Pan Block and the West Qinling Orogen at Lithosphere Scale: Results of Deep Seismic Reflection Profiling. Acta Geosc. Sin. 27, 411-418 (2006).

13. He, C. S. \& Santosh, M. Formation of the North-South Seismic Zone and Emeishan Large Igneous Province in Central China: Insights from P-Wave Teleseismic Tomography. Bull. Seism. Soc. Am. 110, 3064-3076 (2020).

14. Houser, C., Masters, G., Shearer, P. M. \& Laske, G. Shear and compressional velocity models of the mantle from cluster analysis of long-period waveforms. Geophys. J. Int. 174, 195-212 (2008).

15. Flanagan, M. P. \& Shearer, P. M. A map of topography on the $410-\mathrm{km}$ discontinuity from PP precursors. Geophys. Res. Lett. 26, 549-552 (1999).

16. Lu, C., Grand, S. P., Lai, H. \& Garnero, E. J. TX2019slab: A New P and S Tomography Model Incorporating Subducting Slabs. J. Geophys. Res. 124, 11549-11567 (2019). 
17. Kennett, B. \& Engdahl, E. Traveltimes for global earthquake location and phase identification. Geophys. J. Int. 105, 429-465 (1991).

18. van Stiphout, A. M., Cottaar, S. \& Deuss, A. Receiver function mapping of mantle transition zone discontinuities beneath Alaska using scaled 3-D velocity corrections. Geophys. J. Int. 219, 14321446 (2019).

19. Katsura, T. \& Ito, E. The system $\mathrm{Mg}_{2} \mathrm{SiO}_{4}-\mathrm{Fe}_{2} \mathrm{SiO}^{4}$ at high pressures and temperatures: precise determination of stabilities of olivine, modified spinel, and spinel. J. geophys. Res. 94, 15663-15670 (1989).

20. Ringwood, A. E. et al. Composition and Petrology of the Earth's Mantle. McGraw-Hill (1975).

21. Ito, E. \& Takahashi, E. Postspinel transformations in the system $\mathrm{Mg}_{2} \mathrm{SiO}_{4}-\mathrm{Fe}_{2} \mathrm{SiO}_{4}$ and some geophysical implications. J. geophys. Res. 94, 10637-10646 (1989).

22. Hirose, K. Phase transitions in pyrolytic mantle approximately $670-\mathrm{km}$ depth: implications for upwelling of plumes from the lower mantle. J. geophys. Res. 107, ECV 3-1-ECV 3-13 (2002).

23. Yu, Y. G., Wentzcovitch, R. M., Vinograd, V. L. \& Angel, R. J. Thermo-dynamic properties of $\mathrm{MgSiO}_{3}$ majorite and phase transitions near $660 \mathrm{~km}$ depth in $\mathrm{MgSiO}_{3}$ and $\mathrm{Mg}_{2} \mathrm{SiO}_{4}$ : a first principles study. J. geophys. Res. 116, B02208 (2011).

24. Andrews, J. \& Deuss, A. Detailed nature of the $660 \mathrm{~km}$ region of the mantle from global receiver function data. J. Geophys. Res. 113, B06304 (2008).

25. Göğüş, O. H. \& Ueda, K. Peeling back the lithosphere: Controlling parameters, surface expressions and the future directions in delamination modelling. J. Geodyn. 117, 21-40 (2018).

26. Rudnick, R. L. \& Fountain, D. M. Nature and composition of the continental crust: a lower crustal perspective. Rev. Geophys. 33, 267-309 (1995).

27. Christensen, N. I. \& Mooney, W. D. Seismic velocity structure and composition of the continental crust: a global view. J. Geophys. Res. 100, 9761-9788 (1995).

28. Kay, R. W. \& Kay, S. M. Delamination and delamination magmatism. Tectonophysics 219, 177-189 (1993).

29. Göğüş, O. H., Pysklywec, R. N., Şengör, A. M. C. \& Gün, E. Drip tectonics and the enigmatic uplift of the Central Anatolian Plateau. Nat. Commun. 8, 1538 (2017).

30. Foulger, G. R. Are 'hot spots' hot spots?. Journal of Geodynamics 58, 1-28 (2012).

31. Van Decar, J. C. \& Crosson, R. S. Determination of teleseismic relative phase arrival times using multi-channel cross-correlation and least squares. Bull. Seismol. Soc. Am. 80, 150-169 (1990).

32. Zhu, L. \& Kanamori, H. Moho depth variation in southern California from teleseismic receiver functions. J. Geophys. Res. 105, 2969-2980 (2000).

33. Dueker, K. G. \& Sheehan, A. F. Mantle discontinuity structure from midpoint stacks of converted P to S waves across the Yellowstone hotspot track. J. Geophys. Res. 102, 8313-8327 (1997).

34. Eagar, K. C., Fouch, M. J. \& James, D. E. Receiver function imaging of upper man-tle complexity beneath the Pacific Northwest, United States. Earth Planet. Sci. Lett. 297, 141-153 (2010). 
35. Zhu, L. Crustal structure across the San Andreas Fault, southern California from teleseismic converted waves. Earth Planet. Sc. Lett. 179, 183-190 (2000).

36. Xu, M. J. et al. Insight into the subducted Indian slab and origin of the Tengchong volcano in SE Tibet from receiver function analysis. Earth Planet. Sci. Lett. 482, 567-579 (2018).

\section{Figures}

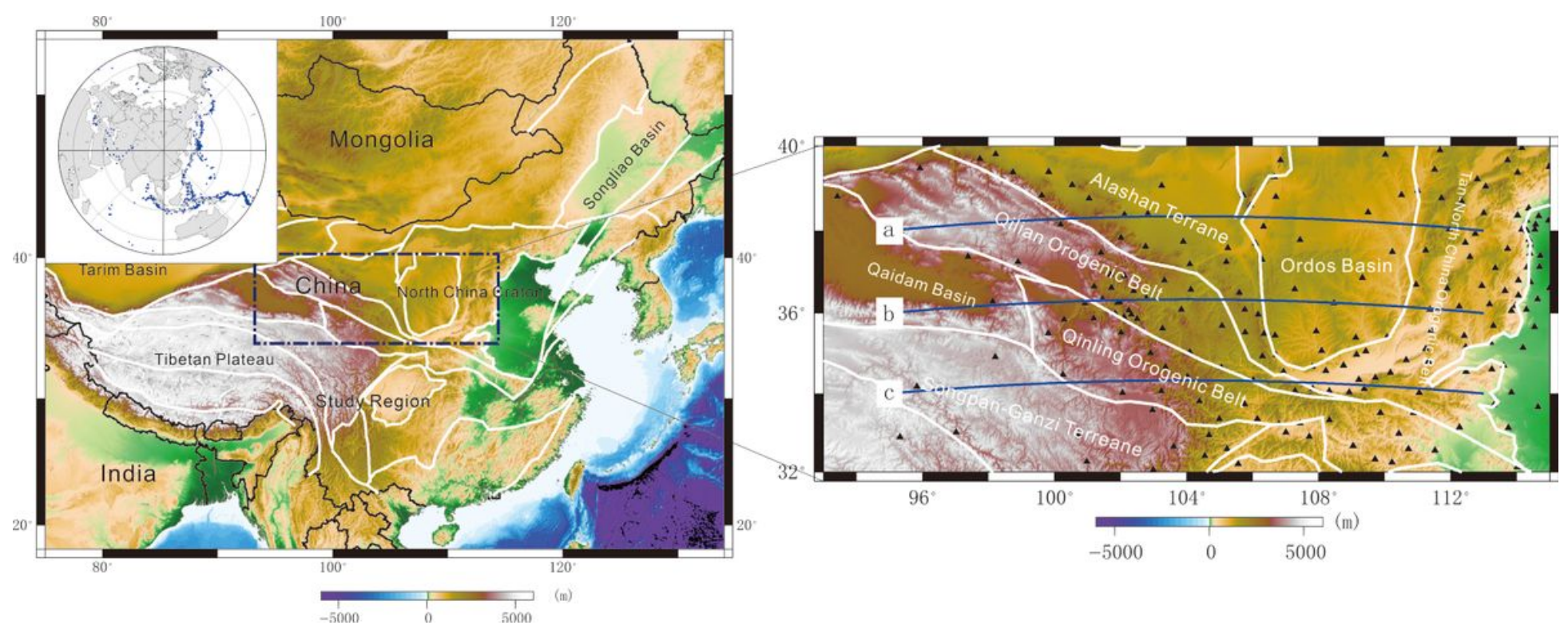

\section{Figure 1}

Left panel: location of the study region. Insert figure of the left panel: distribution of seismic events used in this study. Right panel: tectonic framework and distribution of seismic stations, blue lines: profiles of the P-wave velocity perturbation and CCP stacking of receiver functions. White lines of both panels: geological boundaries [the figure was generated by Chuansong He using Generic Mapping Tools (https://www.generic-mapping-tools.org/)]. 

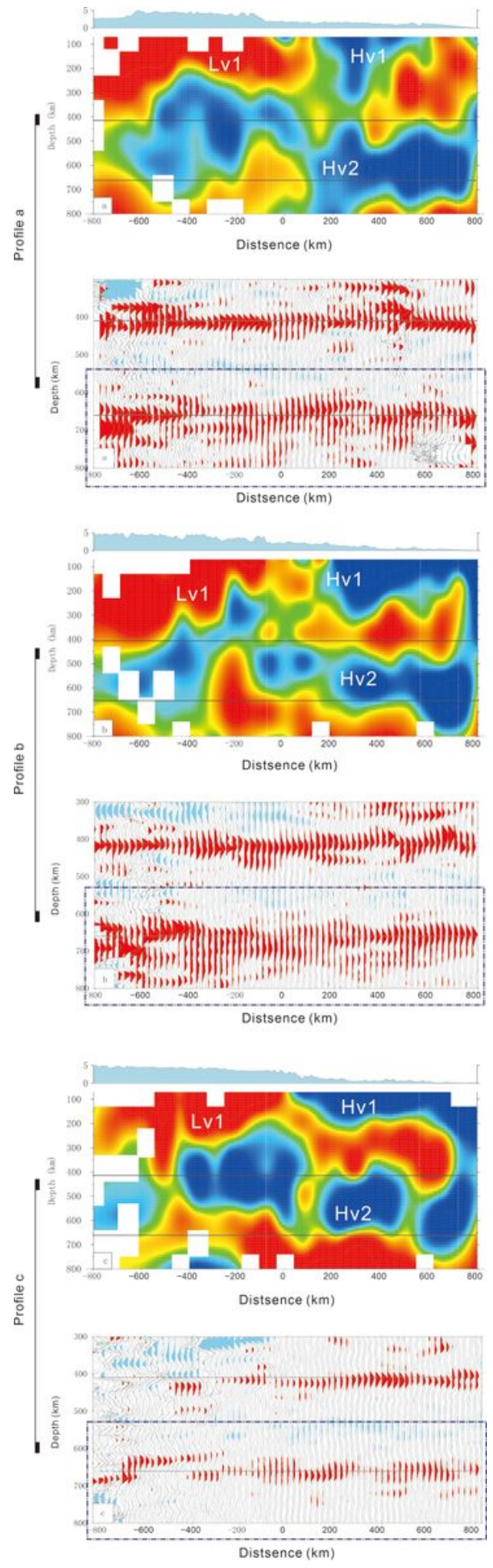

\section{Figure 2}

Latitudinal profiles of the P-wave velocity perturbation (a, b and c) 10(He and Santosh, 2017) and Latitudinal profiles of CCP stacking of receiver functions ( $a, b$ and $c$ ) (Location of profiles, see left panel of Fig. 1; piercing points at depths of 410 and $660 \mathrm{~km}$, see Fig. S2), which is corrected by global P-and Swave 3-D velocity model14. The bootstrapping method is used to calculate the stacked amplitudes (resampling 2000 times in the dataset), and the 95\% confidence level is used to calculate the final mean 
receiver functions (middle lines). Blue and black horizontal lines: depths of $410 \mathrm{~km}$ and $660 \mathrm{~km}$ [the figure was generated by Chuansong He using Generic Mapping Tools (https://www.generic-mappingtools.org/)].
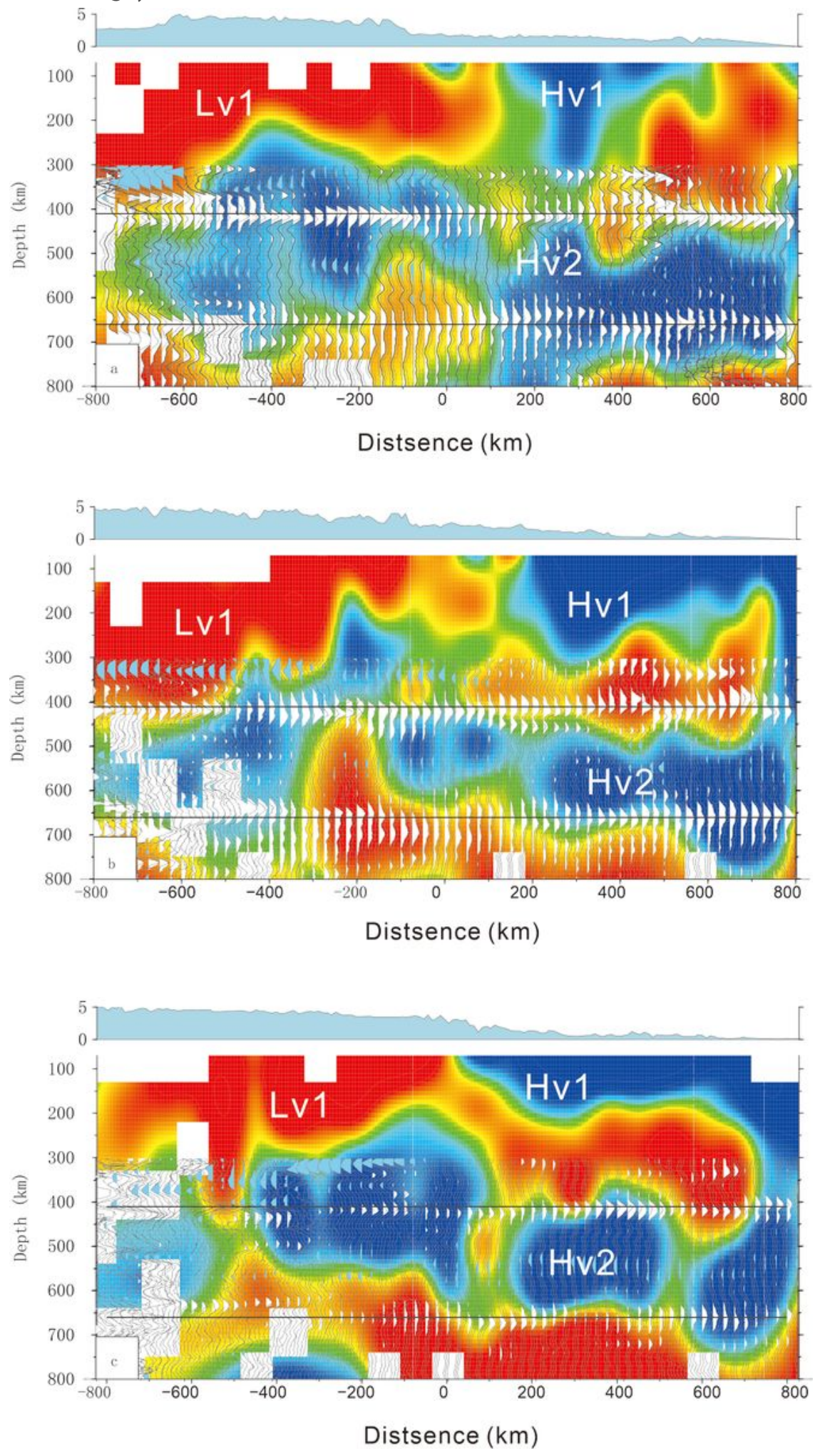

Figure 3

Longitudinal profiles of CCP stacking of receiver functions overlap with those of the P-wave velocity perturbation10 [the figure was generated by Chuansong He using Generic Mapping Tools 


\section{Global model}
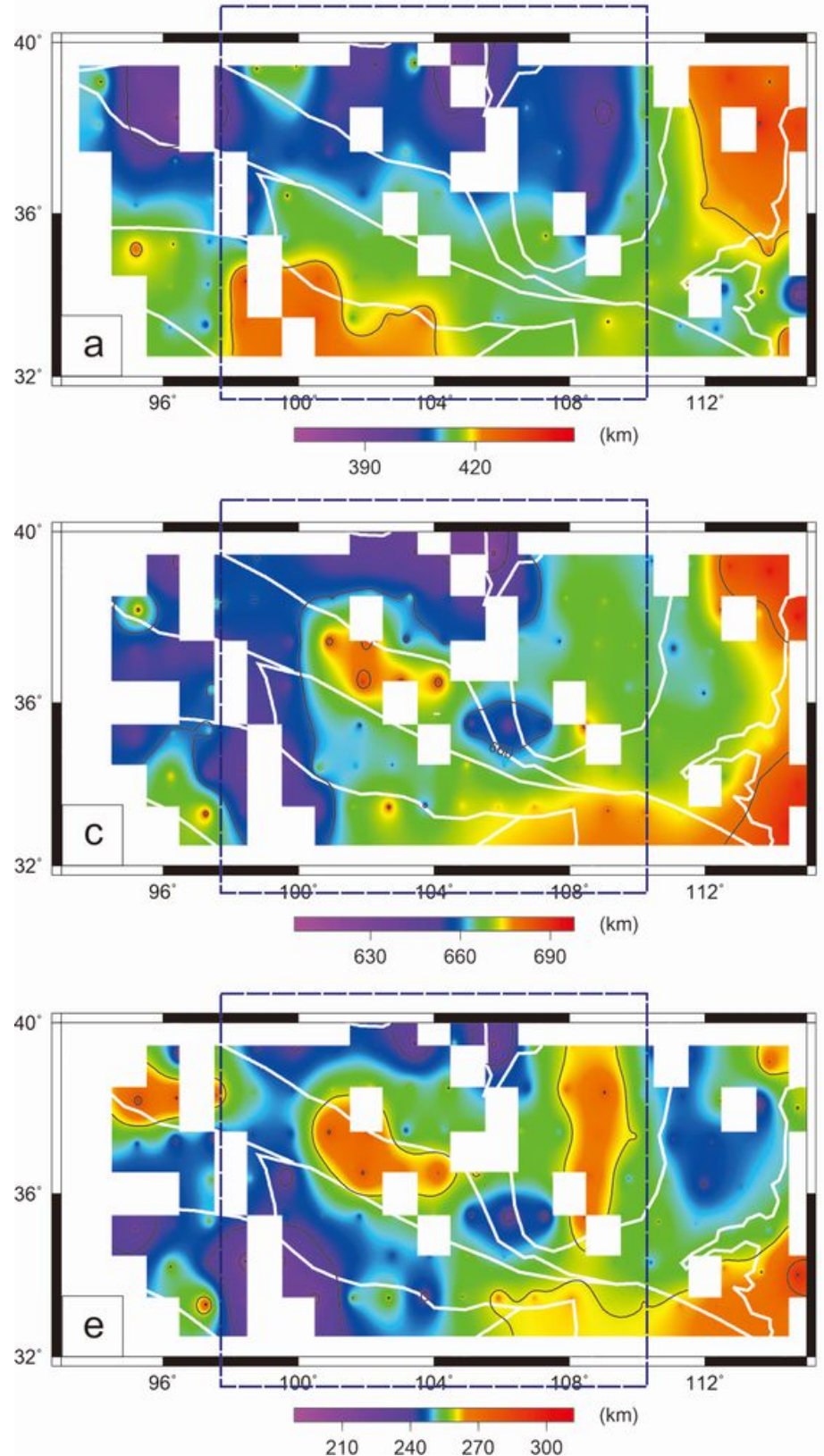

Local model
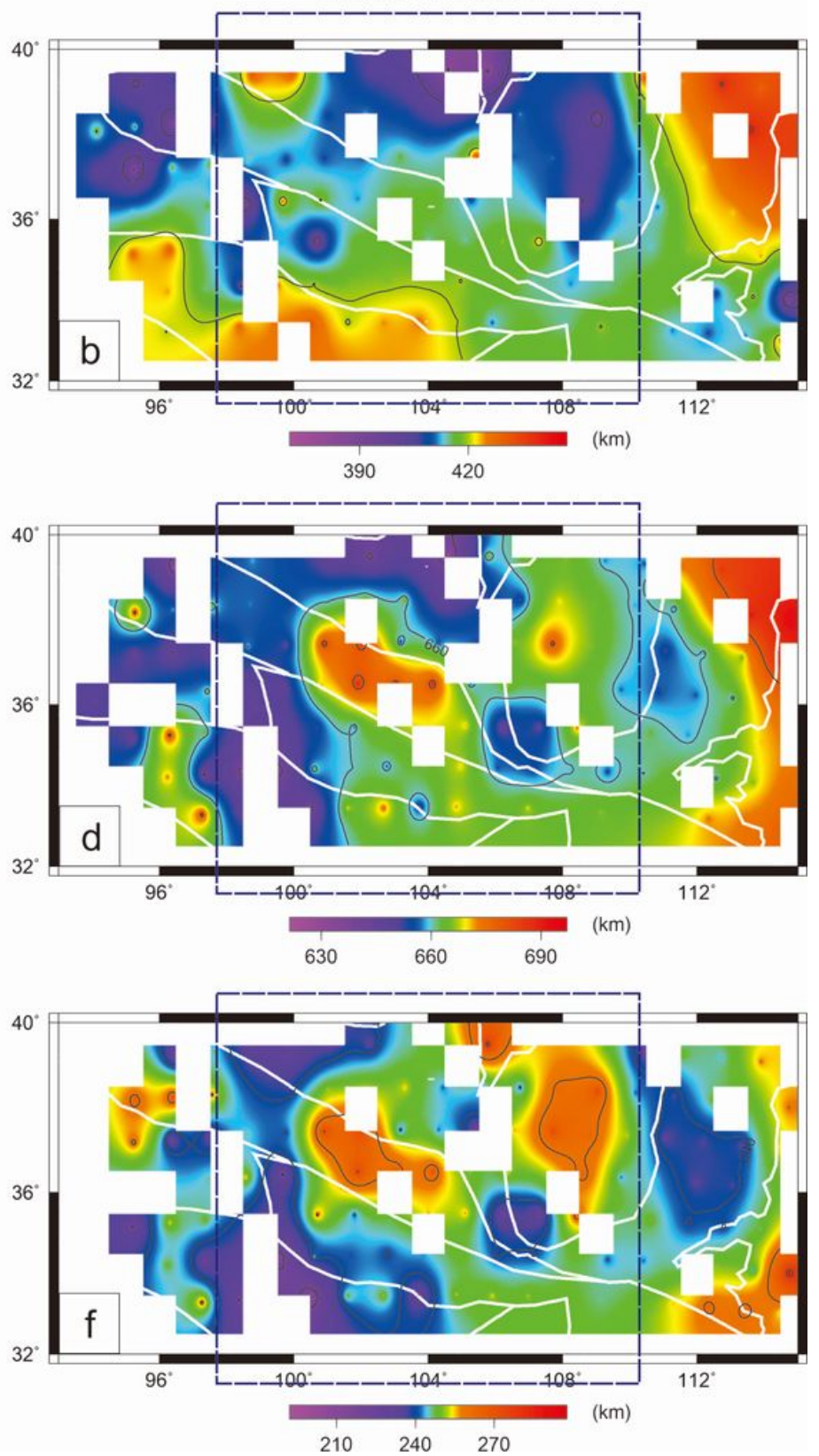

Figure 4

Topography of the $410 \mathrm{~km}$ and $660 \mathrm{~km}$ discontinuities and the thickness of the MTZ. The bootstrapping method is used to calculate the stacked amplitudes (resampling 2000 times in the dataset), and the $95 \%$ confidence level is used to calculate the final mean receiver functions ( $a, b, c$ and d). Depths of the 410 $\mathrm{km}$ discontinuity (a) and $660 \mathrm{~km}$ discontinuity (c) and the thickness of the MTZ (e), which have been corrected on the basis of a global P-and S-wave 3-D velocity model16 (stacking points, see Fig S3). Depths of the $410 \mathrm{~km}$ discontinuity (b) and $660 \mathrm{~km}$ discontinuity (d) and the thickness of the MTZ (f), which have been corrected on the basis of a local 3-D velocity model10, and S-wave velocity is inferred from the AK135 1-D velocity model17 (stacking points, see Fig S3) [The figure was generated by Chuansong He using Generic Mapping Tools (https://www.generic-mapping-tools.org/)]. 


\section{Supplementary Files}

This is a list of supplementary files associated with this preprint. Click to download.

- 0725Supplementarylnformation.docx 